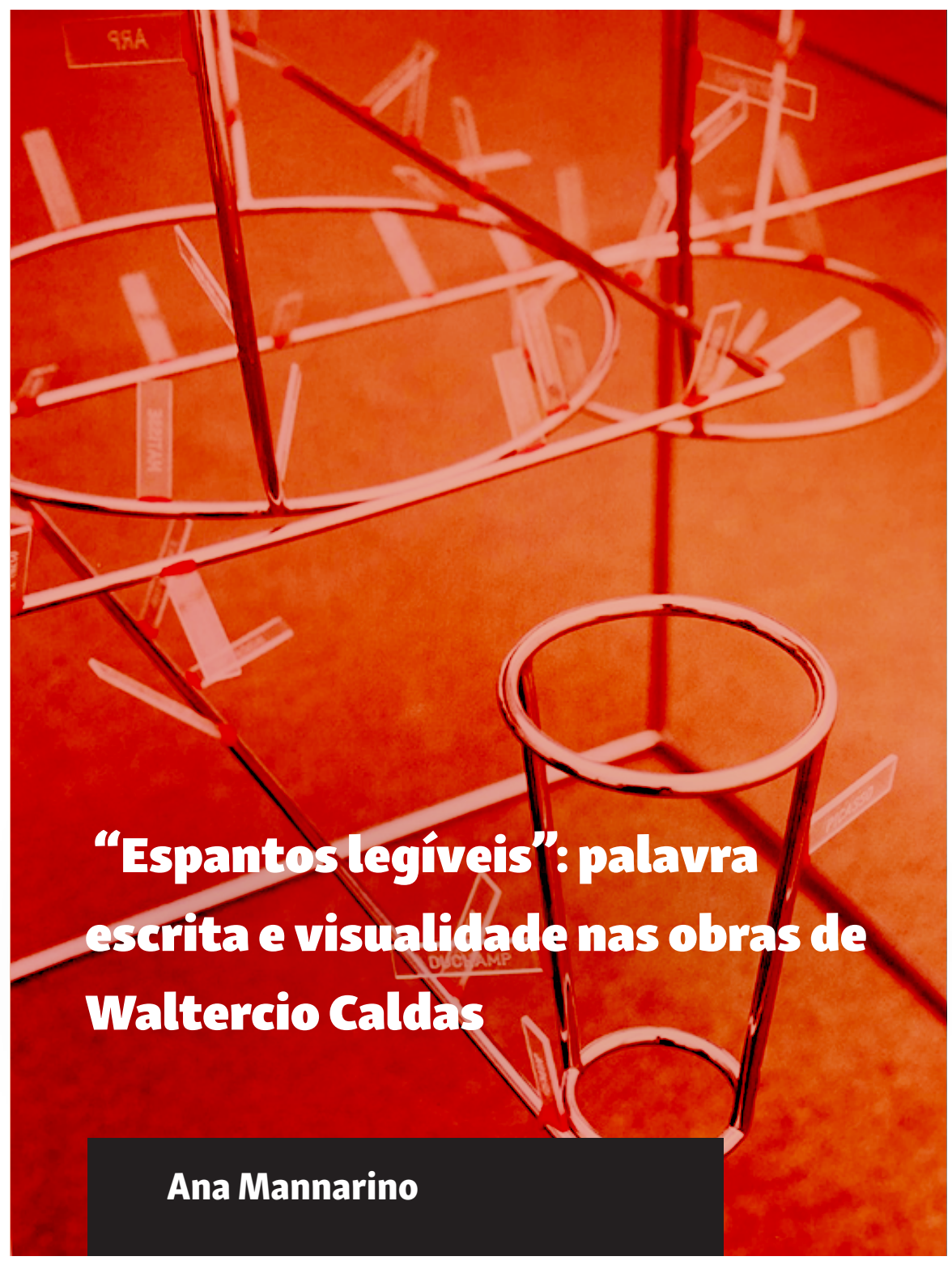

\title{
Como citar:
}

MANNARINO, A. 'Espantos legíveis': palavra escrita e visualidade nas obras de Waltercio Caldas. MODOS: Revista de História da Arte, Campinas, SP, v.5, n. 3,p. 43-70, 2021. DOI: 10.20396/modos.v5i3.8666481

Disponível em: https://periodicos.sbu.unicamp.br/ojs/index.php/mod/article/view/8666481.

Imagem: Waltercio Caldas. Série Veneza (A distância entre...), 1997.

Fotografia Roberto Cecato. 


\section{“Espantos legíveis": palavra escrita e visualidade nas obras de Waltercio Caldas}

\section{"Readable astonishments": written word and visuality in the works of Waltercio Caldas}

\section{Ana Mannarino*}

\section{RESUMO}

O texto aborda a produção do artista Waltercio Caldas (Rio de Janeiro, 1946) a partir do encontro entre palavra escrita e visualidade, refletindo sobre a experiência que esse tipo de combinação é capaz de produzir, tanto do ponto de vista da arte como também do ponto de vista mais amplo da linguagem em geral. Serão analisadas três obras do artista: o ensaio visual Ficção nas coisas (2012), o conjunto de trabalhos intitulado Frases sólidas (2002) e as instalações da Série Veneza (1997). As análises partem da vivência dos trabalhos, na conjunção entre visão e leitura que promovem, de declarações do artista sobre a sua produção que explora a união entre escrita e visualidade, além de textos críticos sobre sua obra e de referências da história da arte que ajudam a pensar seus trabalhos sob o ponto de vista da junção entre palavra e artes visuais: Mallarmé, Marcel Duchamp, o movimento Surrealista e os movimentos concretistas brasileiros. Os experimentos de Waltercio Caldas com a palavra escrita nos levam ao entendimento de que a arte, pela via da experiência sensível, possibilita a reflexão sobre a linguagem e seus limites, tensionando-a de um modo que a via do conceito não seria capaz de fazê-lo.

\section{PALAVRAS-CHAVE}

Waltercio Caldas. Palavra escrita e visualidade. Ficção nas coisas. Frases Sólidas. Série Veneza.

\section{ABSTRACT}

The text addresses the artistic production of Waltercio Caldas (Rio de Janeiro, 1946) considering the encounter between written word and visuality. It reflects on the experience that this type of combination is capable of producing, both from the viewpoint of art and from the broader viewpoint of language in general. Three works by the artist will be analyzed: the visual essay Fiction in Things (2012), the set of works entitled Solid Sentences (2002) and the installations of the Veneza Series (1997). The 
analyzes are based on the experience of the works, in the conjunction between vision and reading they promote, on the artist's statements about his production that explores the union between writing and visuality, as well as on critical texts about his work and references from the history of art that contribute to understand Caldas' production from the viewpoint of the junction between written word and visual arts: Mallarmé, Marcel Duchamp, the Surrealist movement and the Brazilian concrete movements. Waltercio Caldas' experiments with the written word lead us to the understanding that art, through sensitive experience, enables the reflection on language and its limits, tensioning it in a way that would not be possible through concept.

\section{KEYWORDS}

Waltercio Caldas. Written word and visuality. Fiction in Things. Solid Sentences. Veneza Series.

\footnotetext{
A primeira lembrança que tenho desse encontro [com os livros] veio dos livros infantis especialmente alguns dos quais uma lacuna entre o texto e as imagens se apresentava de uma forma intrigante. Dou um exemplo: uma casa desenhada na floresta ilustra um conto de fadas, mas a legenda desorienta: 'algo inusitado acontecia ali' (Caldas, 2013: 190, grifos do autor).
}

A obra de Waltercio Caldas desenvolveu-se ao longo das décadas sem que o conjunto possa ser compreendido a partir de um denominador comum formal - embora a forma visível seja determinante no jogo de relações que ela suscita. Jogo que articula visível e invisível, presença e ausência, operando na disjunção existente entre percepção imediata da obra e suas remissões. Nesses deslocamentos, nessa poética do intervalo, do hiato, da fenda, a linguagem verbal se interpõe, seja nos títulos, seja pelas palavras incorporadas ao trabalho, permitindo novas relações que dizem respeito à própria obra do artista, mas também uma interrogação sobre a linguagem articulada - suas possibilidades e limitações, e sua conexão com a vivência, a partir da obra.

Para pensar o papel desempenhado pela linguagem verbal nos trabalhos de Waltercio Caldas, e como as relações entre palavra, espaço e imagens produzem, no jogo orquestrado pelo artista, situações singulares que ultrapassam as possibilidades de significação da ordem do discurso e do conceito, relacionamos aqui três trabalhos do artista: o ensaio visual Ficção 
nas coisas (2012), o grupo de trabalhos intitulado Frases Sólidas (2007) e o conjunto de instalações Série Veneza (1997). Esses trabalhos serão analisados em uma sequência que é inversa à cronológica, começando com o mais recente e finalizando com o mais antigo. $O$ estudo centra-se naquilo que os conecta: os modos complementares de se pensar a palavra escrita associada à visão, às imagens e às formas, saindo do livro, do espaço da página, situação mais familiar desse encontro entre texto e visualidade, e indo em direção a uma gradativa dispersão da palavra no espaço ambiente, em situações que contudo se vinculam, ao proporem experiências que subvertem nossa relação habitual com a linguagem.

Vários textos críticos a respeito de seu trabalho coincidem em apontar como referências para a sua produção uma dupla vertente. Por um lado, o artista alimenta-se das tradições construtivas brasileiras, a arte concreta e, sobretudo, neoconcreta, guardando com elas muitos traços em comum, principalmente no que diz respeito a uma apreensão fenomenológica do espaço e da geometria, a partir de suas instalações e esculturas. $O$ artista declara também a arquitetura moderna brasileira como uma de suas principais referências. Por outro lado, conjuga essa tradição mais direta, do modernismo brasileiro, com o movimento surrealista e também com a produção e procedimentos artísticos de Marcel Duchamp (Salzstein, 2009; Osorio, 2004). Seu interesse pelo surrealismo, mais do que uma referência direta a determinadas obras, artistas ou iconografia, segundo depoimento do próprio artista, se concentra no que ele chamou de "operação surrealista" (Caldas, 2012a). Tal operação diz respeito à possibilidade, inaugurada pelos artistas surrealistas, de admitir os sonhos, algo além da realidade do mundo, como tema para a arte, como matéria real de trabalho, e não como uma alegoria ou metáfora de uma realidade. Seu interesse no surrealismo diz respeito à liberdade para a arte de se voltar para o desconhecido, o indeterminado, para aquilo que não existe.

A produção de Waltercio Caldas se volta, portanto, para dois momentos da história da arte que articularam palavra e visualidade: os 
movimentos surrealista e Dada (na figura de Marcel Duchamp), por um lado, e os movimentos construtivos brasileiros, por outro. A arte construtiva brasileira, tanto na poesia como nas artes plásticas, em experimentos que trazem a escrita (livros-poema, poemas-objeto, livros-objeto), exploraram as qualidades gráficas da palavra, sua disposição espacial na página e no espaço ambiente, desconstruindo a linearidade da leitura. Exploraram a palavra também do ponto de vista fenomenológico - sua espacialidade e temporalidade associadas à carga semântica que ela carrega, ativando nossas memórias e vivências. Muitos trabalhos de Waltercio Caldas que fazem uso da escrita têm nesse jogo entre a palavra e o espaço-tempo da obra um ponto de partida. Já a relação com o surrealismo e o movimento Dada se manifesta nos jogos de palavras, nas operações que expõem a fragilidade da lógica da linguagem articulada, nas disjunções entre obra e título e nos aforismos visuais. Seu trabalho conjuga, assim, dois caminhos distintos trilhados em direção à interrogação da linguagem verbal. Ambos a articulam em situações de confronto com a visualidade, com o espaço empírico e com o mundo das imagens, situações que desestabilizam as relações de significação segundo o confortável uso cotidiano da palavra. Uma outra referência importante para o artista, sobretudo nas questões que aqui nos interessam, que envolvem a palavra escrita e a visualidade, é a obra de Mallarmé, principalmente no poema Un coup de dés.

A experiência poética de Mallarmé no século XIX é uma fonte comum para os movimentos apontados acima na articulação entre linguagem verbal e espaço, entre leitura e visão. Tanto na tradição construtiva brasileira dos anos 1950 como nos trabalhos surrealistas, na arte e na literatura, a poesia de Mallarmé desponta como um divisor de águas, um deflagrador de possibilidades para o experimento com a palavra escrita. O recurso a Mallarmé como uma referência direta por um artista contemporâneo, como Waltercio Caldas, e também como uma referência indireta, à qual se somam as experiências concretistas no Brasil e o surrealismo, revela 
uma leitura particular da arte do século XX e de seus desdobramentos contemporâneos. E que se aproxima da leitura que Rancière faz do período moderno via Broodthaers e seu trabalho-homenagem a Mallarmé (Rancière, 2005). A obra de Waltercio Caldas se alinha portanto a esse entendimento do modernismo que coloca Mallarmé e seu poema numa posição crucial para o período: aquele que o centra na busca por uma distinção entre arte e não-arte na investigação de uma correspondência utópica entre palavras e formas. Utopia que, no trabalho de Waltercio Caldas, assim como no de Broodthaers, é, contudo, desfeita: ambos os artistas partem já de sua impossibilidade. Broodthaers, na negação da espacialidade do texto. Waltercio Caldas, em seus "espantos legíveis" (Caldas, 2013), que parecem indicar uma correspondência entre palavras e formas para então desfazê-la, e situar-nos no hiato entre elas, operação com a qual nos defrontamos sobretudo em trabalhos como Série Veneza, Frases Sólidas e Ficção nas coisas.

$\mathrm{Na}$ declaração do artista que citamos na abertura deste texto, ele relata como, diante do estranhamento provocado pela reprodução de suas esculturas em imagens bidimensionais, deparou-se com o problema mais geral da linguagem, assumindo-o em sua obra e partindo já da impossibilidade de uma linguagem transparente, de um significado de existência independente do significante, da utopia tipicamente moderna do próprio do signo. O "estado de imagem", a "noção alterada" das coisas permeará sua poética, que procura expô-los nas relações que propõe, retirando-os do estado subjacente em que se confundem com as coisas de que falam. A palavra escrita tem, nessa dinâmica, um papel fundamental. Ela contribui, seja nos livros, seja nos objetos ou instalações, para provocar o que o artista chamou de "espantos legíveis", no descompasso entre o visto e o lido, entre imagem e texto, que situa a obra no intervalo, na lacuna que a justaposição entre o legível e o visível produz. Sua obra, sobretudo na conjugação entre leitura e visão, entre texto e imagem, entre palavra escrita e objeto, põe em evidência a relação, a diferença, para, em alguns trabalhos, provocar 
a imaginação do leitor, remetendo-a a lugares e situações improváveis. Nesses casos, os hiatos se estendem e se abrem para que o leitor/vidente os preencha, estabelecendo um espaço de relações particulares. Em outros, os envios são interrompidos e reiniciados, para retornarmos constantemente às relações propostas pelo trabalho, situando-nos nesses hiatos por demais estreitos para que possamos preenchê-los - podemos apenas constatá-los. Nesses casos, ao conduzir-nos para esse vão entre duas situações que se combinam, o artista não nos envia além. O espaço "entre" não é um fora, embora não seja presente, nem visível, nem delimitável. A dicotomia entre presença e ausência se abala, e a procura pelo "aparecer", recorrente nos discursos do artista, é assim uma pergunta que, no seu trabalho, se desfaz ao ser formulada. O "estado de imagem" de sua obras o levou a concluir que um trabalho proposto tem inúmeros possíveis desdobramentos que fogem a seu controle. Isso é evidente na reprodução bidimensional de esculturas tridimensionais no espaço plano delimitado de um livro, mas se dá também em toda relação entre obra e sua recepção, entre palavra e coisa, entre o dito e o visto, entre palavra e significado, enfim.

\section{Ficção nas coisas}

Ficção nas coisas (2012) é um ensaio visual de 32 páginas criado por Waltercio Caldas para a revista Serrote (Caldas, 2012b), aparecendo na publicação de 240 páginas entre outros ensaios que conjugam texto e imagem de um modo tradicional. Nele, Waltercio Caldas levanta problemas que só são possíveis porque esse trabalho integra totalmente o circuito comercial e de produção de um impresso tal como uma revista. Ao contrário de grande parte de seus livros, que não são manipuláveis e são obras de arte únicas, o ensaio foi impresso em tiragem industrial, publicado, comercializado e distribuído como uma revista de circulação de escala mediana, acessível 
ao público em geral, que pode viver a experiência de ler/ver e folhear o ensaio, de manipulá-lo. O trabalho foi, assim, projetado especialmente para a situação específica da publicação, e joga com os parâmetros que o restringem, explorando essas circunstâncias para daí extrair seu interesse.

$O$ artista, em uma fala sobre esse trabalho (Caldas, 2012a), afirmou que uma de suas preocupações ao estruturá-lo foi o contraste entre o ritmo de leitura que ele queria induzir e o ritmo costumeiro de leitura de um texto em uma revista. Ao lermos um texto convencional, demoramo-nos um tempo considerável em cada página, alternando o movimento linear e de vaivém das sequências das palavras com os respiros das imagens. Na leitura de ensaios comuns, o movimento de mudança entre uma página e outra é uma operação que passa, discretamente, sob a continuidade do texto. No ensaio visual, diferentemente, segundo o artista, "algo se trava, muda de ritmo, ou anda mais rápido ou mais devagar, mas não é certamente o ritmo dos textos. É nessa mudança de ritmo que comecei a trabalhar algo que me interessasse" (Ibidem). Explorando essa diferença de ritmo, o ensaio propõe então uma mudança de atenção, que se volta para o objeto livro, para suas características intrínsecas, as quais, na leitura de textos comuns, desempenham um papel coadjuvante - embora fundamental e determinante na sua estrutura. Essa mudança de atenção é uma exigência comum a quase todos os trabalhos do artista. Eles constantemente propõem situações que, seja pela estranheza, seja pela falta, ou por uma sutil incongruência, exigem de nós, para o acompanharmos, uma absorção que nos mobiliza, retirando-nos do fluxo regular a que aderimos na percepção rotineira das coisas, do tempo e do espaço. O ensaio Ficção nas coisas é bastante exemplar nesse sentido. $O$ leitor da revista pode passar rapidamente pelas páginas do ensaio visual para continuar lendo os textos, folheando as páginas dominadas por amplas áreas brancas como quem se desvencilha de uma intervenção indesejada. Mas se quiser adentrá-las, interagir com elas, lê-las (ou ler/vê-las), precisará deixar-se absorver pelo ritmo que impõem, 
interrogá-las, ou melhor, decifrá-las. Talvez seja nesse sentido que Sonia Salzstein (2002), referindo-se aos livros de Waltercio Caldas, afirme que eles são objetos que veem, mais do que são vistos: são eles que nos interrogam, que exigem de nós uma resposta, e não o contrário.

Ao vivenciarmos o ensaio, estamos diante de um objeto que não é simplesmente um "objeto intermediário" ou um "objeto-distância", um veículo para realidades das quais nos separamos no tempo e no espaço definição de livro para Adolfo Montejo Navas (2002). Ficção nas coisas põe em questão essa remissão que é própria ao livro, e, para tanto, adota uma estratégia que se desenvolve em duas frentes distintas. A primeira diz respeito à atenção que o ensaio exige para as circunstâncias criadas pelo objeto livro, particularidades que permanecem normalmente nos bastidores desse objeto e que, no ensaio, são protagonistas. A segunda refere-se ao tratamento dado ao que seria o conteúdo das páginas: texto e imagem. Sobre as particularidades do objeto livro, o artista enumera algumas das características que, para ele, foram determinantes na elaboração do ensaio, defendendo que um livro "fala a sua própria língua" (Caldas, 2013). São eles: a visão das páginas de par em par, obrigando-nos a compará-las; a distância mais ou menos determinada com que nos relacionamos com os livros, na adequação entre visão e manipulação, e que propiciam uma certa relação de intimidade com o objeto; o vértice da encadernação, elemento de atração da atenção, tanto visualmente como também por ser a estrutura em torno da qual o livro se sustenta em tensão com o nosso manuseio. Acrescentamos também a superfície branca da página, cuja emergência no ensaio em áreas extensas e variadas contrasta com a regularidade destinada a elas nas delimitações da grade das demais páginas da revista. Mas é sobretudo na divisão em páginas, unidades que se sucedem no tempo e no espaço, e que integram um conjunto maior - o restante da publicação - que o artista explora as características do livro, na passagem de uma página para a outra, nessa sucessão de planos operada pelo leitor, que constitui um livro. 


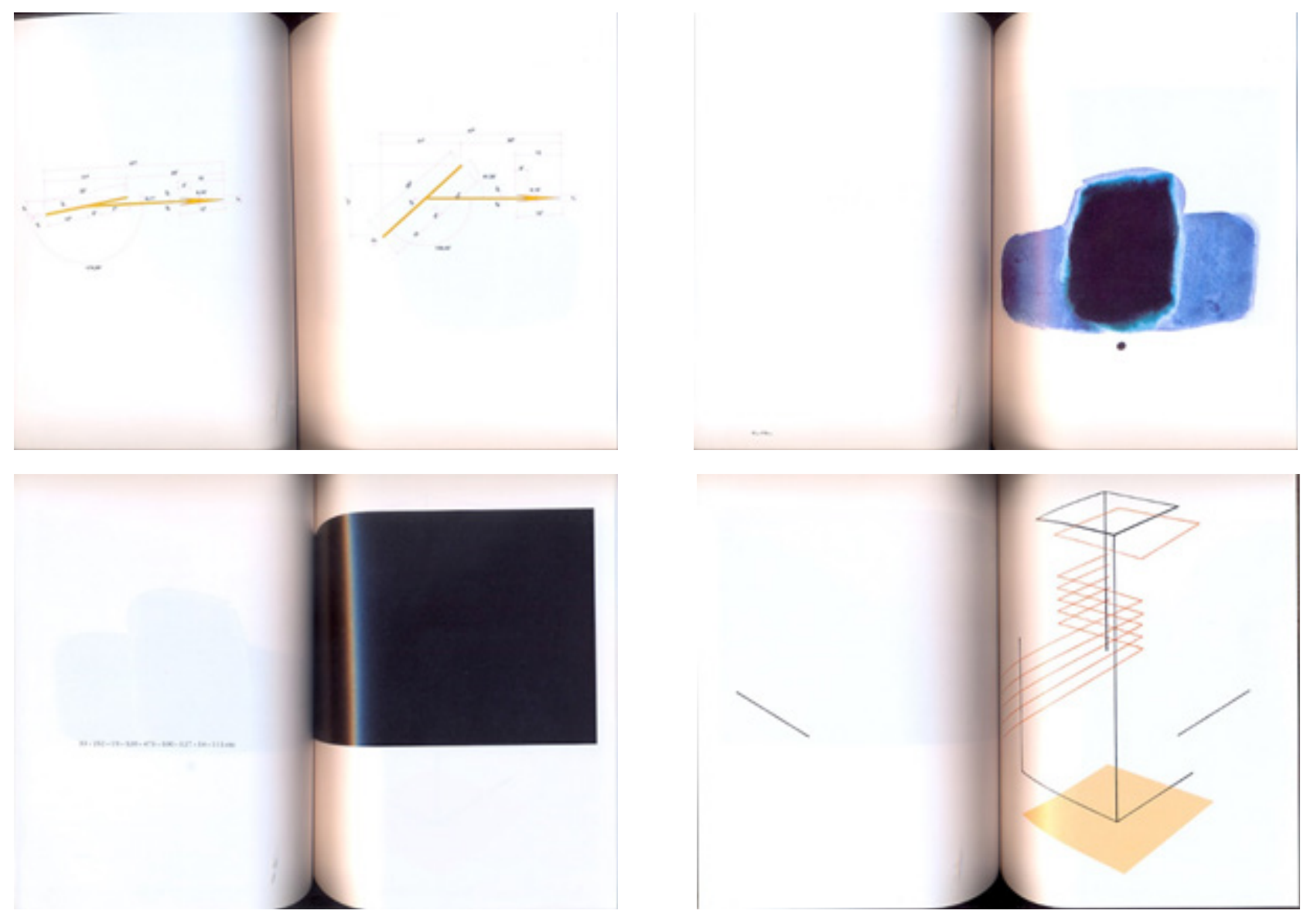

FIGS.1-4. Waltercio Caldas. Páginas duplas do ensaio visual Fiç̧ão nas coisas. Publicado na Revista Serrote em março de 2012. Formato fechado da publicação: $24 \times 18 \mathrm{~cm}{ }^{1}$

As imagens, segundo as palavras do artista, "parecem estar de passagem pelas páginas, nenhuma está instalada. Algumas tratam até da passagem do tempo necessária ao folhear de uma página” (Caldas, 2012a). Ele se refere a um par de páginas em que aparece a inscrição “15:30", como uma indicação horária, seguido de um outro par de páginas que traz, por sua vez, "15:31", chamando a atenção para a diferença de instantes a que cada par pertenceria numa hipotética linha do tempo. Ele quer, desse modo, mostrar as páginas não como lugares diferentes, mas como um mesmo lugar, por onde as imagens passam em movimento. Também o uso recorrente de setas que reforçam o sentido do virar das páginas, da esquerda para a direita, assim como a disposição das imagens na página, que sugerem um 
deslocamento do olhar para a direita, reforçam o sentido do movimento. Essa passagem se torna mais forte ainda, sobretudo, pelo sentido da leitura que, quase sempre restrita a uma única linha, faz o movimento em uma direção apenas, sem retornar o olhar, como aconteceria no vaivém de um texto de várias linhas. Frequentemente, esse movimento linear é acompanhando de linhas horizontais que o reforçam, desenhadas nos fios gráficos, ou sugeridas no uso de reticências e travessões estendidos. Waltercio Caldas frisou, em seu depoimento, que a dinâmica de passagem do ensaio se intensifica na circularidade sugerida pela palavra que o encerra: "etc.", ou seja, "e outras coisas", encerramento de uma enumeração de modo genérico porém conclusivo, que remeteria o leitor, no entanto, de volta ao início do ensaio, em seu título, "Ficção nas coisas". Waltercio Caldas declarou que o final que retorna ao início leva o ensaio a construir "de forma metafórica uma esfera impressa", pelo movimento circular dos planos em sequência em torno de um eixo, que se fecha na união entre fim e início. Essa ideia do ensaio cujo final reenvia o leitor ao início, sugerindo uma circularidade na leitura, remete, diretamente, ao poema Un coup de dés de Mallarmé. Nele, a frase final "todo pensamento emite um lance de dados" faz-nos retroceder à frase-título de seu início, "um lance de dados jamais abolirá o acaso", que percorre as páginas do poema até algumas páginas antes da frase final. Para Maurice Blanchot, referindo-se ao poema de Mallarmé, "[essa sentença] é a cláusula e é a abertura, é a invisível passagem em que o movimento em forma de esfera é constantemente fim e começo" (Blanchot, 2005: 359).

As relações desse ensaio de Waltercio Caldas com o Un coup de dés não se restringem no entanto à circularidade sugerida pelo texto que quer comunicar o final ao início. Ela está também na explicitação da estrutura do livro de que viemos de tratar: as páginas pensadas para serem vistas de par em par; a tensão do vértice que as une, na ocupação das páginas que o atravessa; o protagonismo do suporte nas extensas áreas brancas. Essas foram preocupações de Mallarmé também em seu poema, pensado 
igualmente em contraposição a outros impressos com o qual se confrontaria, diretamente ou não. Também em Un coup de dés, tal tratamento singular dado ao texto, integrando-o à estrutura de seu suporte, no movimento da leitura associado à disposição espacial, evidencia o movimento de passagem das páginas e nos obriga a uma mudança de atenção, retirando-nos do fluxo regular da percepção do tempo e do espaço. Blanchot comenta esse aspecto do poema, que seria capaz de transformar as relações de espaço pelo movimento que se dá no tempo. Nele, "o espaço que não existe mas 'se escande', 'se interioriza', se dissipa e repousa segundo as diversas formas da mobilidade do escrito, exclui o tempo ordinário" (Ibidem: 352-353).

Podemos ver, no ensaio Ficção nas coisas, como esses instantes do tempo ordinário, que se sucederiam irreversivelmente segundo um ritmo regular, se contrapõem aos instantes estendidos e reversíveis dos pares de página em sequência. Nas mesmas duas duplas de páginas que trazem a indicação temporal, 15:30 e 15:31, respectivamente, indicando um minuto que segue $o$ outro, esse minuto pode durar menos que um segundo, ou pode se estender indefinidamente, ao nos demorarmos aleatoriamente em uma das páginas, contrariando a cronometragem sugerida pelos números indicados. Podemos ir e vir dentro do ensaio, no tempo indeterminado e descontínuo próprio ao livro. A dinâmica proposta pelo artista, em que predomina a direção horizontal, acompanhando o sentido de leitura e a passagem das páginas, se desenvolve com contrapontos que promovem esses retornos: em elementos verticais que a intercalam, e em movimentos regressos, sugeridos quando as imagens a que se referem os dizeres das páginas direitas ocupam as páginas da esquerda, ou quando o encontro entre as páginas, o vértice da encadernação, parece atrair os elementos nelas dispostos. Somos, assim, envolvidos no jogo proposto por esse objeto que se entrelaça com as imagens e palavras impressas.

A segunda frente da estratégia desenvolvida por Waltercio Caldas nesse ensaio para desestabilizar o caráter de remissão próprio ao livro, 
"objeto intermediário" e "objeto-distância", diz respeito ao tratamento dado às imagens e ao emprego das palavras, o próprio texto do ensaio. Com relação às imagens, o artista procura explorar o que ele definiu como "estado de imagem das coisas", a operação que transforma coisas em imagens. $O$ ensaio poderia se chamar, segundo o artista, "Ficção nas coisas impressas". Nele, as imagens "nasceram para serem impressas (...) e eu as escolhi porque essas imagens têm autonomia com relação ao objeto que as originou, do qual elas partiram" (Caldas, 2012a). Assim, o interesse das imagens e desenhos no ensaio reside não naquilo a que remetem, mas no seu próprio estado de imagem impressa. Elas apontam para um mundo exterior para retornarem a elas mesmas, em um movimento circular. Elas fazem o movimento de nos enviar para algum lugar, mas esse lugar é vago, ambíguo, vazio. Retornamos então às imagens, para nos fixarmos brevemente nelas até sermos novamente induzidos ao movimento de remissão. Ficamos transitando nesse espaço intermediário, na lacuna entre as coisas e seu estado fictício. A atenção à diferença entre imagens e coisas é análoga à diferença entre o dito e o visto, entre escrita e imagem. E o título nos sugere, pela junção entre as palavras "ficção" e "coisas" a extensão dessa diferença para além do ensaio, e para as próprias coisas.

Esse movimento não seria possível no ensaio sem o movimento da leitura, sem as palavras escritas que acompanham a visão das imagens. Waltercio Caldas empregou nesse trabalho o que chamou de "palavras invertebradas": "não estão contextualizadas em nenhum tipo de relação a não ser a questão gráfica. Elas dizem somente o que dizem e desaparecem depois de dizerem somente o que disseram. Elas não estão relacionadas a outro texto, mas ao próprio texto do ensaio" (Ibidem). São palavras que parecem ter sido retiradas do seu contexto, conectivos e pronomes adjetivos sem os substantivos referidos, intercalados com reticências; ou que falam de tempo, de passagem e de mudança sem se referirem a nada especificamente; ou que introduzem um discurso sem fazê-lo: "E... ou..."; “...e que mudam de nome, sempre..."; “é=”; “em seus tempos próprios ------------- irreversíveis"; 
"zzzzz"; "por que não antes ------------ ou depois?"; "por exemplo: simples: etc.". O objeto do discurso é o próprio ensaio visual e as questões que levanta, é a falta de contexto ou de um significado delimitável, a não ser a simples mudança e passagem das páginas, o ir e vir da temporalidade entrecortada do livro, o intervalo indefinido entre coisas e imagens, entre significante e significado, na livre movimentação da linguagem, criando um jogo de exterioridades, de puros significantes. Para o artista, pelo uso das palavras, pode-se até mesmo "legitimar relações inaugurais entre um autor que não escreve e um leitor que não lê" (Caldas, 2013: 191). Assim, o ensaio se situa justamente nessa "relação inaugural" entre autor e leitor, nas palavras e imagens que não apontam para fora desse estado intermediário. $O$ próprio das palavras é falar de coisas ausentes. Essas palavras não falam de coisas, não são nada além da ausência. A ênfase nas relações se desvela, também, na proximidade dessas palavras às cifras, aos números, cotas, medidas, recorrentes no ensaio ${ }^{2}$.

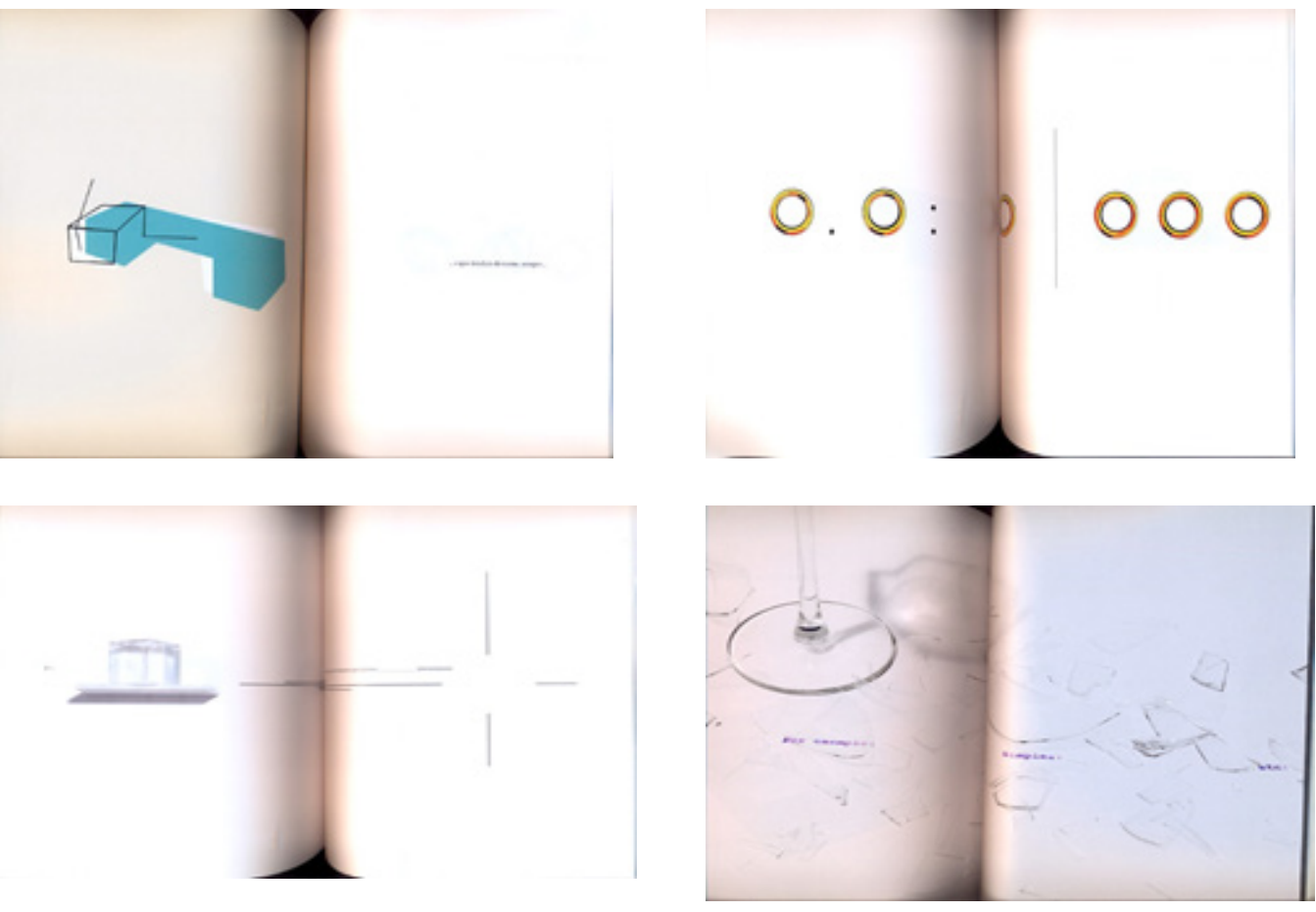

FIGS. 5-8. Waltercio Caldas. Páginas duplas do ensaio visual Ficção nas coisas. Publicado na Revista Serrote em março de 2012. Formato fechado da publicação: $24 \times 18 \mathrm{~cm}$. 
As imagens, nesse ensaio, não estão subordinadas às palavras, nem há, tampouco, um projeto de correspondência entre formas, ideias e palavras, como sugerido em Mallarmé e, a partir dele, em vários momentos do modernismo, como no trabalho de Apollinaire, Rodtchenko e Schwitters (Rancière, 2005), ou na poesia concreta e neoconcreta brasileiras. O trabalho de Waltercio Caldas não compartilha da utopia moderna da busca de uma identidade entre palavra, espaço e ação. Palavras e imagens, no ensaio em questão, interagem como em um jogo, ora divergem, ora se complementam, sugerindo relações criadas circunstancialmente e não com o propósito de se estabelecerem analogias, conformidades, seja da leitura em relação à visão, seja de ambas em relação a algum ideal exterior a elas. Quando a correspondência entre texto e imagem parece ser apontada, isso acontece para que ela seja logo desfeita. Um exemplo é a dupla de páginas de Ficção nas coisas que apresenta um retângulo preto na página da direita e uma legenda na página da esquerda. A incongruência das múltiplas dimensões da legenda $(33$ × 252 × $19 \times 320$ × 475 × 500 x 127 × 54 × $115 \mathrm{~cm}$ ) nos envia para a página ao lado e, onde esperamos ver a imagem correspondente, há apenas um retângulo preto, a falta de imagem. Nada se esclarece, nenhum ponto de encontro se apresenta, e texto e imagem correspondem-se assim na ausência que nega a identidade. Esses trabalhos não indicam, pela confrontação entre texto e imagem, dois estados de uma mesma coisa ou significação, mas, ao confrontá-los, abre caminho para se questionar a própria possibilidade de haver uma significação comum possível por trás desses diferentes estados.

\section{Frases sólidas}

No conjunto de trabalhos conhecidos como Frases sólidas (2002) a palavra abandona os limites do livro para habitar o espaço, entre os objetos. O espaço fictício do livro tem o poder de planificar e aproximar objetos e escrita nas suas superfícies em sequência, por mais heterogêneos que possam parecer. Fora do livro, as palavras, nas Frases sólidas, aparecem, em geral, 
nas superfícies sobre as quais os objetos repousam. Reconhecemos porém que a superfície, tal como o livro, não deixa de ser o suporte para palavras e objetos. Mas, ao contrário desse último, ela não planifica, não uniformiza nem absorve, ela é o fundo comum que permite o embate entre umas e outros. No confronto direto entre eles, os objetos interferem na remissão que a palavra isolada provocaria, e os dizeres interferem, por sua vez, na percepção dos objetos, criando perturbações nas relações de identidade, explorando o estranhamento entre significante e significado a que o cotejo entre palavras e coisas pode induzir. No texto "O espelho crítico", de 1975, Ronaldo Brito fez algumas considerações sobre a obra de Waltercio Caldas que seguem sendo pertinentes para pensarmos esses trabalhos feitos em 2002. Ele defende, então, que a potência do trabalho de Caldas residiria na operação de manipulação de signos, na subversão de seus usos cotidianos, criando estranhamentos quanto aos seus significantes. Seus trabalhos expõem, segundo Brito, a "loucura implícita na própria linguagem”, agindo sobre o senso comum e pondo em "xeque nosso domínio lógico sobre o mundo". Para o autor, o trabalho de Waltercio Caldas é um "produtor de estranhamentos. Ao desatar o nó que une significante e significado, ou que une algum objeto à sua função dominante, ele reabre um espaço que a experiência cotidiana luta para conservar fechado" (Brito, 2005: 342).

Nos trabalhos da série Frases sólidas, a aproximação espacial entre escrita e objetos não tenta nivelá-los, como na relação proposta na superfície impressa de uma página, nem compartimentá-los, como na separação entre título e objeto. Ela promove esses estranhamentos, na contaminação entre ler e ver, de um modo peculiar. Os objetos não são imagens, são sólidos, eles têm peso e volume. Por um lado, eles parecem poder emprestar às palavras uma parte de sua realidade e solidez, procurando recuperar um pouco da abstração sobre a qual a linguagem verbal se estrutura. Parecem, apenas, pois a relação estabelecida entre uns e outros não é nunca uma simples correspondência, mas uma dupla remissão que deflagra o movimento digressivo da linguagem. As "palavras invertebradas", empregadas em 
muitos dos trabalhos dessa série, constroem, no conjunto, a impressão de que toda a linguagem é invertebrada. Os objetos, na sua solidez, poderiam ser um contraponto a essa sensação de debilidade, nas configurações propostas, tendem não a serem vistos como coisas, mas a serem lidos também como signos, partes de uma sentença ou "frase sólida". Mais do que emprestar concretude às palavras, são os objetos que perdem a sua solidez, dissolvendo-se no jogo do signo.

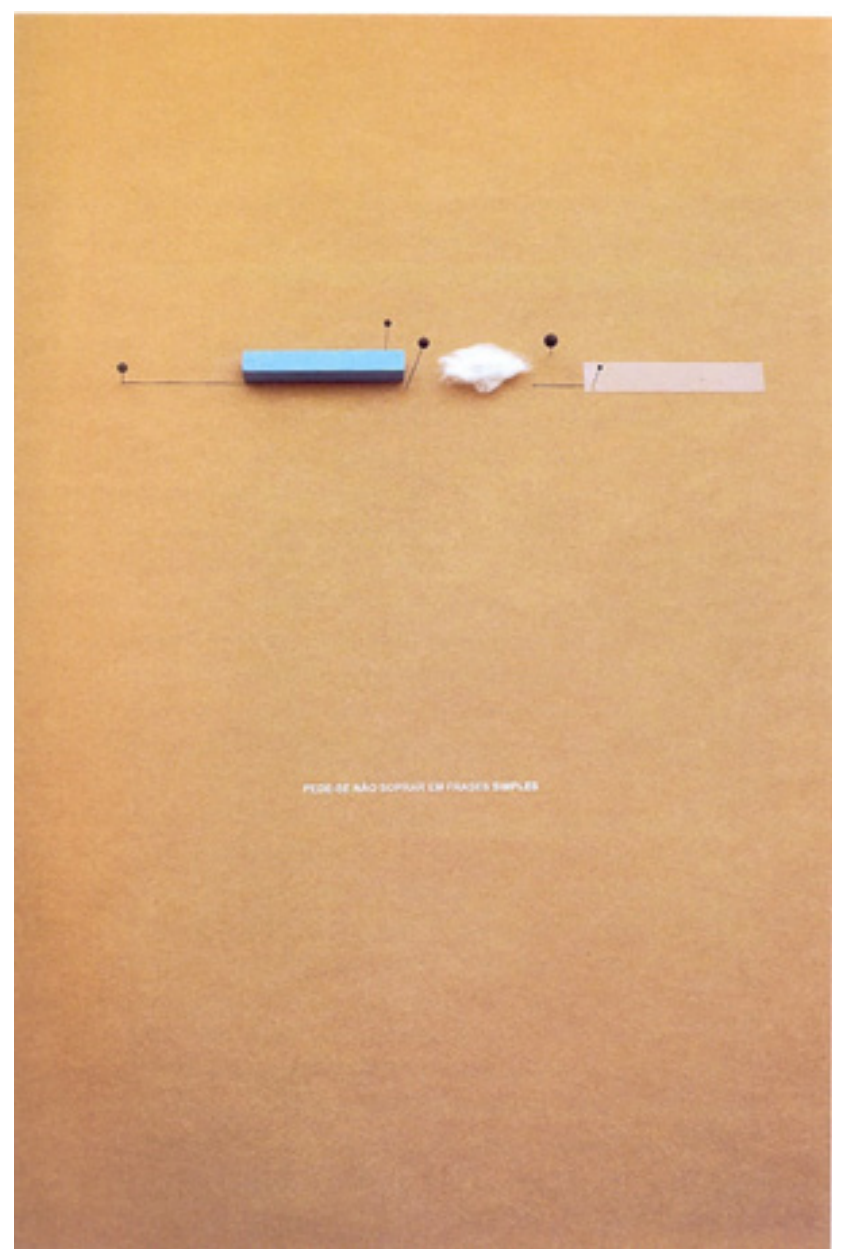

FIG. 9. Waltercio Caldas. Frases Sólidas (Pede-se não soprar em frases simples), 2002. Reproduzido em Caldas (2009:107). Fotografia Vicente de Mello e página.

Esses trabalhos expõem a tensão entre linguagem verbal e matéria. Os objetos parecem também poder alterar a disposição e a configuração montada pelo artista a qualquer momento, são conjuntos instáveis, frágeis 
circunstâncias que em nada lembram a fixidez do livro. Embora, ao serem expostos, os conjuntos estejam protegidos em vitrines, percebemos a instabilidade das situações como possibilidades. A pedra de Homero imaginário pode rolar e deixar a posição que ocupa nas bordas do livro que compõe o conjunto. $O$ livro pode se fechar ou ter a página virada, e a frase que é parte do trabalho ficaria então incompleta. $O$ algodão de Pede-se não soprar em frases simples pode voar e perder a forma, para isso basta o sopro mencionado pelas palavras. Pela respiração, pelo sopro, pelo ar que se movimenta, a palavra falada também se faz coisa, é também matéria. Pela fala, o frágil equilíbrio do conjunto poderia se desfazer, demonstrando a continuidade entre o sistema fônico e o da escrita na matéria e no mundo concreto, diluindo as divisões entre interior e exterior em que se baseiam as noções tradicionais de escrita (Derrida, 2011).

Do mesmo modo, quase todos os conjuntos podem facilmente se desfazer na precariedade dos agrupamentos formados, eles não estão aprisionados em nenhum "estado de imagem" de uma fotografia, estão no estado transitório do mundo das coisas e do espaço que habitamos. As palavras escritas compartilham assim a efemeridade dos conjuntos. Elas dependem da simbiose entre leitura e visão, no sistema completo que, nesses trabalhos, engloba os objetos, seus materiais, a distribuição no espaço, a situação espacial e a configuração visível da escrita. A espacialização da escrita que, na página, incorpora os brancos, fazendo do tempo da leitura o tempo estendido, indeterminado da duração, tem nessas obras um desdobramento radical. O espaço concentrado da página se dissipa e as palavras reverberam o seu isolamento no espaço sem limites definidos, ao passo que se dispersam no mundo, entre os objetos. Esses trabalhos nos remetem, na sua concisão verbal, ao conceito de "imagem" em poesia para Pound, que concentra, em um instante, um certo "complexo intelectual e emocional" (Pound, 1976). Por outro lado, sua disposição no espaço condiz com a "dispersão volátil" e a extrema irrupção, o movimento de diáspora que 
caracteriza, segundo Blanchot (op. cit.), o movimento da linguagem. Tensão entre a máxima concentração e a difusão, sempre no limite de desfazer-se, é aquilo com que nos deparamos nessas Frases Sólidas.

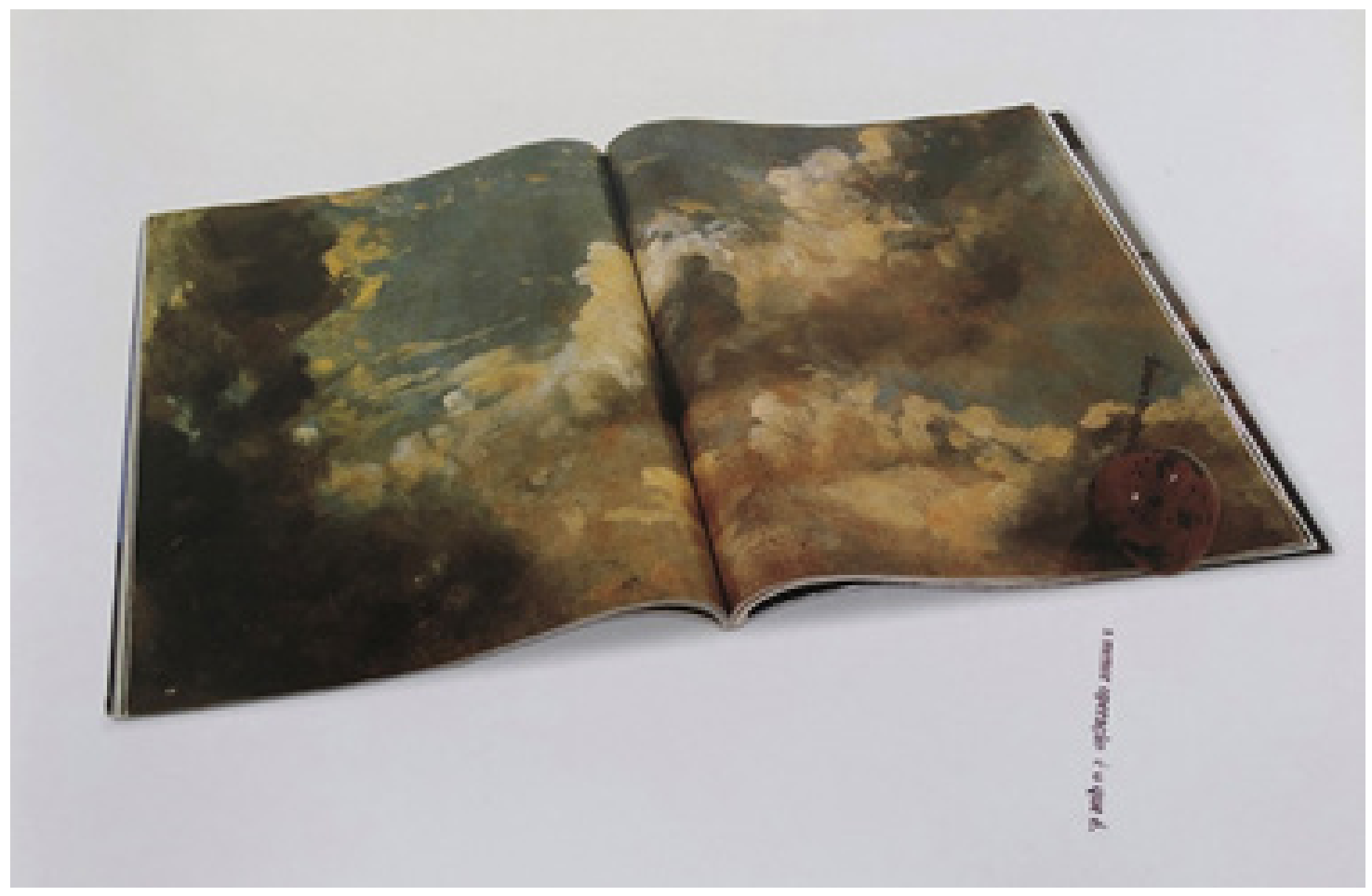

FIG.10. Waltercio Caldas. Frases Sólidas (Homero Imaginário), 2002. Reproduzido em Pérez-Barreiro (2012:87).

\section{Série Veneza}

Sonia Salzstein referiu-se aos trabalhos da série Frases sólidas como "instalações compactas". Esses trabalhos, assim como os livros e as caixas de Waltercio Caldas, têm um contraponto importante nas instalações ou "salas" do artista em que aparecem, também, palavras escritas. No texto "Espaço solúvel", de Paulo Venâncio Filho (2009), sobre a exposição Salas e abismos, o autor observa como essas "salas" culminam em uma dissolução 
poética do espaço, em contraposição à densidade e concentração espaciais de algumas obras mais antigas, como Condutores de percepção (1969). Nesse texto, Venâncio Filho considera o "aparecer" do trabalho de Caldas como uma das questões centrais de sua poética. Tal concepção se desenvolve na observação de que as "salas" solicitam um reajuste constante de nosso mecanismo sensorial, exigindo-nos um tempo específico de apreciação a cada nova sucessão, no entrelaçamento do espaço e do tempo e na experiência de uma duração fenomenologicamente indefinida (Venâncio Filho, 2009). O problema do "aparecimento" da obra a conecta com a tradição da arte brasileira no movimento neoconcreto 3 . Não podemos, contudo, nos aproximarmos de sua obra do mesmo modo com que nos aproximaríamos de um não-objeto neoconcretista. Faz parte de sua poética uma tensão entre objeto artístico e instituição, ao jogar constantemente com a maleabilidade da definição de arte. Também o uso da palavra, embora possamos conectá-lo à palavra nos livros-poemas e poemas-objetos neoconcretos, se dá de outro modo, propondo para a linguagem verbal e visual relações que exploram alusões e conexões que incluem repertórios que apontam para além da experiência imediata da obra. O recurso recorrente ao repertório da história da arte, pelo uso de reprodução de imagens de obras e também pela referência a nomes de artistas de diferentes épocas e lugares, é exemplar para pensarmos essa diferença. Nesse sentido, a obra Série Veneza (1997) permite-nos refletir sobre como atuam as palavras em tais situações espaço-temporais criadas pelo artista, e como o emprego da palavra escrita a complexifica e a transforma. A leitura exige novos ajustes perceptivos, novas relações com o espaço, criando uma tensão entre aquilo que está explicitamente dito - o nome dos artistas - e aquilo a que esses nomes remetem, entre presença e ausência, entre espaço e tempo atuais e aquilo que é referido pela palavra. 


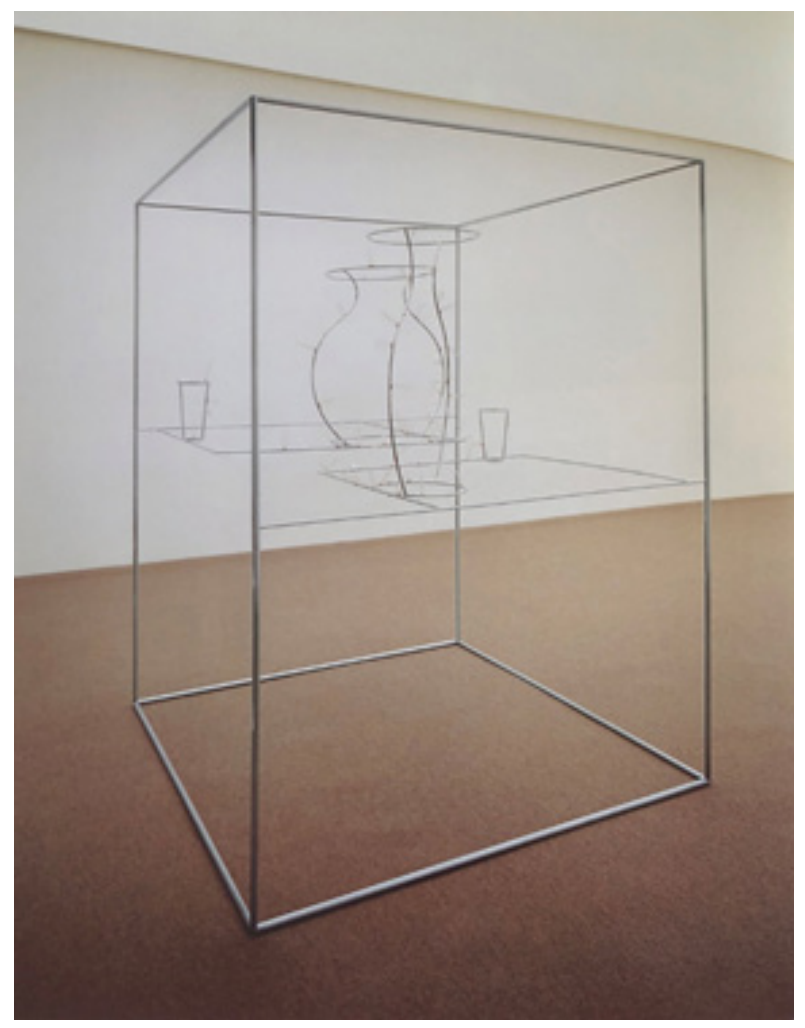

FIG. 11. Waltercio Caldas. Série Veneza (A distância entre...), 1997. Reproduzido em Caldas (2001: 22). Fotografia Roberto Cecato.

A instalação é composta por quatro cubos lineares vazados, feitos em tubos metálicos que, dentro do limite espacial que formam, abrigam formas, também lineares. Essas formas desenham no espaço contornos que sugerem objetos de uma natureza morta (vasos, copos), ou formas esculturais da tradição (pedestais, e formas ovais que lembram as cabeças das esculturas de Brancusi). A instalação se divide em quatro módulos: Sem título, RodinBrancusi, A distância entre... e $O$ transparente. Interessa-nos destacar aqui os três primeiros, que trazem pequenas placas de acrílico transparente unidas aos tubos metálicos, contendo palavras inscritas na cor branca. Em Sem 
título, todas as placas trazem a mesma inscrição que se repete: "senza titolo". Em Rodin-Brancusi, as placas contém ora o nome de um dos escultores referidos no título, ora de outro. E, em A distância entre..., as diversas placas trazem nomes de diferentes artistas, de variadas épocas: Matisse, Dürer, Duchamp, Caravaggio, Renoir, Picasso, Arp, Fontana, Schwitters, Daumier, Gauguin, Munch, Watteau, Velázquez, Bosch, Tiziano, Man Ray, Giacometti, Seurat, El Greco, Ingres, Vermeer, Boccioni, Vantongerloo, entre outros. O trabalho exige de nós diferentes aproximações: seus elementos se situam em algum lugar entre a instalação, a escultura e o desenho, acrescidos ainda da palavra escrita. Vemos o conjunto no espaço ambiente, circulamos entre os trabalhos, e sua visão se transforma com o movimento. As formas que aparecem no interior dos cubos exploram essa circulação, e os desenhos sugeridos pelas esculturas por pouco não chegam a formar-se, aparecem para se desfazerem em seguida, conforme percorremos nosso trajeto pela sala. Os desenhos parecem estar por serem feitos, sugerem vasos e copos, mas com o movimento se abstraem e desaparecem. Ao nos aproximarmos mais detidamente da obra, vemos as pequenas placas com os dizeres. As palavras, invisíveis a certa distância, ao nos acercarmos, porém, exercem grande poder de atração. As letras de fôrma utilizadas, na clareza de seu desenho, embora estejam em escala reduzida e em uma situação de baixo contraste, têm a força de interferir vigorosamente entre as formas apenas sugeridas pelos tubos metálicos. Tal como em um livro, o trabalho tem, assim, momentos distintos de leitura. Partimos de uma visão geral do conjunto, a seguir nos acercamos e vemos os quatro momentos intercalados, nas formas escultóricas, para então nos determos um pouco mais e lermos o texto das placas. Formas visíveis sugeridas e palavras legíveis se contaminam mutuamente, e as formas que se insinuam se imiscuem entre as imagens e lembranças que os nomes evocam. 


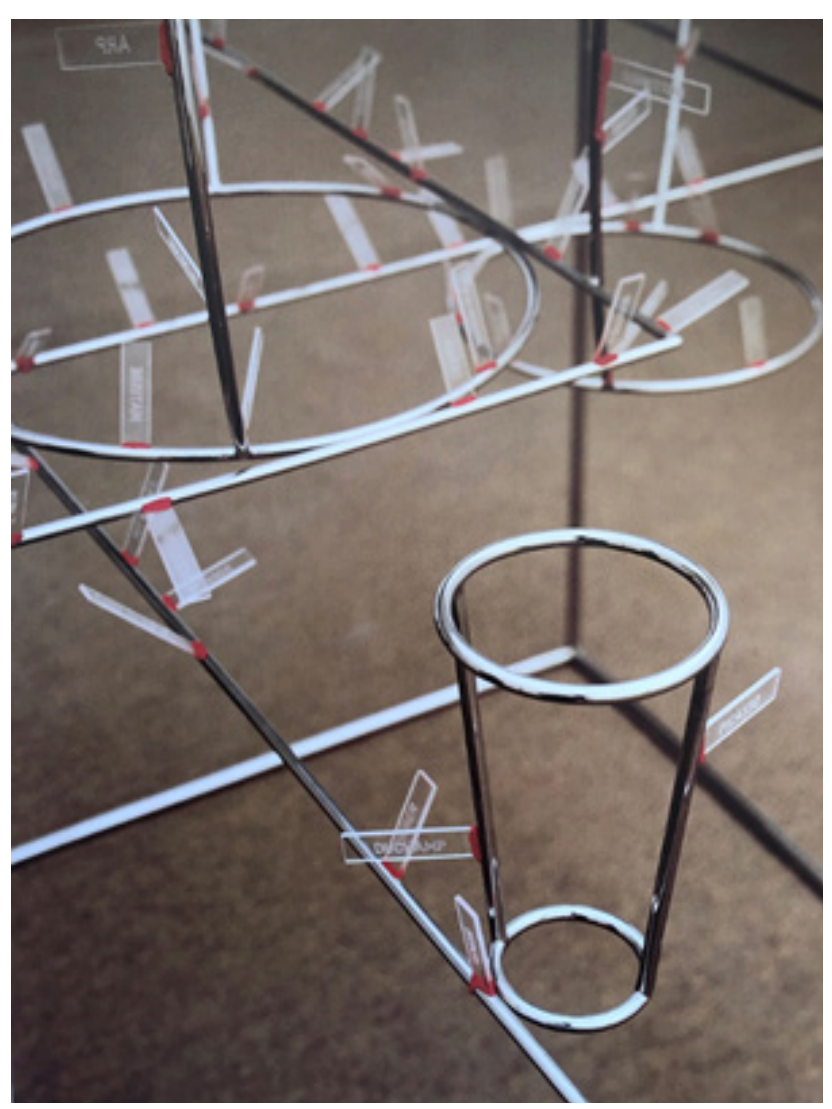

FIG. 12. Waltercio Caldas. Série Veneza (A distância entre...), 1997. Reproduzido em Caldas (2001:23).

Fotografia Roberto Cecato.

No módulo A distância entre..., essa relação se dá de um modo especialmente incisivo. Nos dois módulos anteriores, as palavras se valem da repetição, que acabam por manter com o trabalho uma relação próxima àquela que encontramos entre obra e seu título, em que um nome ou dizer perpassa toda a nossa percepção da obra - embora, na Série Veneza, esse título não seja externo à obra, ele integra, nas placas, as formas e espaços do trabalho. Em A distância entre... as palavras que aparecem não repetem o título. São um grupo de nomes que evoca, cada um deles, um rico e extenso elenco de obras, e que, no conjunto, traz para o momento da visão-leitura um vertiginoso e heterogêneo complexo de imagens. Em 
nosso horizonte virtual é posta assim parte significativa da tradição da arte ocidental, condensada em algumas palavras, em contraste com a visão atual, econômica, entremeada de vazios e transparências, e quase sem cor, exceto pelos pontos vermelhos da cola que une as placas aos tubos. Uma avalanche de imagens vem a nossa memória, imprecisas, variantes, umas interferindo nas outras, sempre em confronto com o que temos diante dos olhos, os frios tubos metálicos, os amplos espaços, a letra de desenho contemporâneo, impessoal e regular.

Em entrevista a Ligia Canongia, Waltercio Caldas se refere a essa obra como um comentário sobre a suspensão do tempo histórico e do espaço geográfico (Caldas, 1998), ao trazer para uma mesma situação espaço-temporal realidades díspares - recurso que o discurso histórico e a cultura dos museus permitem, e que o trabalho, no emprego da palavra nas condições propostas por Caldas, explicita. A distância entre um artista e outro, no tempo, no espaço, ganha a dimensão unificadora da tradição. $O$ que os aproxima não é um encadeamento temporal nem um entrelaçamento espacial, tampouco uma rede de referências mútuas, mas a livre escolha do artista que elegeu esses nomes como seu repertório particular. Ele nos é, assim, proposto, não como um elenco sucessivo, em uma sequência pré-determinada, nem tampouco como uma imagem-texto que se apresente de uma vez à visão. Mas como um conjunto disposto no espaço, em múltiplas direções, e que depende do percurso aleatório do espectadorleitor, no tempo da apreciação da obra de arte, para que seja apreendido. Conforme circulamos no espaço, nos deparamos com os diferentes nomes que vão, aos poucos, se somando na leitura entremeada pelas longas pausas impostas pelos intervalos espaciais que os separam. Assim como vamos, ao longo dos anos, nos familiarizando com diferentes artistas ao acaso, e suas obras se acumulam em nosso repertório pessoal, ou, assim como em um museu, os conjuntos de obras de diferentes artistas se sucedem e se acrescentam na experiência da visita, vivemos, na visão-leitura desse 
trabalho, a soma gradativa de camadas de obras, de imagens, de repertórios. Temos a experiência condensada desse acúmulo, intercalada com a visão da escultura que serve de suporte para os nomes e que, no percurso necessário à leitura, transforma-se, impondo-se, cambiante, à visão. $O$ trabalho, assim como outras instalações do artista, é uma expansão da escritura no espaço. Mas, por outro lado, ele traz algo da propriedade totalizante do livro para o tempo da obra de arte, ao condensar em uma unidade espaço-temporal, pelo recurso à palavra escrita, uma quantidade de obras, evocadas pelos nomes dos artistas, que em muito extrapola as possibilidades físicas dessa unidade. A apreensão dessa totalidade, contudo, não se dá pelo objeto que se põe em movimento, tal como se dá em nossa manipulação de um livro, mas somos nós mesmos que nos movemos para apreendê-la. Nesse trajeto, nos deparamos com longos intervalos. $O$ espaço entre as formas lineares se impõe. No movimento, as esculturas se transformam, os desenhos da natureza-morta aparecem e desaparecem. Na leitura de um texto convencional, a neutralidade da disposição espacial, em sua sequência linear, não interrompe o nosso processo habitual de formação de imagens mentais. Aqui, o que vemos e aquilo que os nomes evocam se confrontam. No silêncio dos intervalos há espaço para que as lembranças reverberem, sendo, porém, interrompidas pelas mudanças na configuração das esculturas conforme nos movemos, e sendo, também, continuamente, transformadas pelas interferências das novas e sucessivas leituras. Na fusão entre o que lemos e o que vemos reside uma das questões primordiais do trabalho. Ele explora a abertura dessa região fronteiriça que ocupa, referindo-se, por um lado, a um conjunto de artistas sem mostrar suas obras, nenhuma delas, e, por outro, apresentando-nos à visão uma configuração que exige de nós um constante rearranjo de nossa atenção. Oscilamos entre o que lemos e o que vemos, e nada no conjunto é estável, nem visão, nem aquilo que a leitura evoca. Deslocamo-nos assim no espaço formado pelo intervalo entre visão atual e virtual, movimento lento que responde ao ritmo da leitura de 
pequenos nomes separados por grandes intervalos, e ao ritmo do percurso do espectador móvel em torno das obras. $O$ trabalho tem assim um tempo para sedimentar-se. Depois de oscilarmos entre a visão e a remissão, o movimento se estabiliza numa zona de incômoda indefinição, em que a dicotomia entre presença e ausência se dissipa.

Nos trabalhos Ficção nas coisas, Frases sólidas e Série Veneza, Waltercio Caldas cria situações que nos permitem experimentar de um modo singular as conexões entre palavras, imagens, formas, objetos. O uso e percepção costumeiros das linguagens - verbal, imagética, gráfica - são perturbados ao sofrerem deslizamentos nos seus papéis habituais, criando lacunas, interrupções, exigindo do leitor-vidente uma outra percepção do tempo, do espaço e das relações de significação. O livro é ponto de partida para diversos trabalhos do artista, ao realizar tanto objetos artísticos em forma de livro como livros de artista. Nas três obras que aqui discutimos, o livro é também uma questão fundamental, na sua ambiguidade entre concentração e dispersão, entre atual e virtual, e na sua capacidade de coordenar linguagens díspares em um único sistema. Ficção nas coisas relaciona-se de um modo mais direto com o livro, na sua estrutura, nas suas dimensões manipuláveis e na delimitação espacial, ao mesmo tempo múltipla e unificada. Frases sólidas abandona o espaço fictício do livro para confrontar o espaço empírico, páginas aumentadas e sem limites precisos incorporam no seu sistema objetos, e os limites desfeitos do livro desfazem também as correspondências estáveis das relações de significação. Na Série Veneza, a leitura exige a ação do corpo que percorre a obra para experimentá-la, temos o desenvolvimento do livro no mesmo ambiente que envolve também nosso corpo e a dispersão das palavras no espaço. A espacialização da palavra, em situações distintas, confronta o atual e o virtual, presença e ausência, interrogando o próprio do signo e as relações de identidade, nos espantos legíveis sugeridos pelo artista. 


\section{Referências}

BLANCHOT, M. O livro por vir. São Paulo: Martins Fontes, 2005.

BRITO, R. O espelho crítico (1975). In: Experiência crítica. São Paulo: Cosac Naify, 2005. CALDAS, W. Depoimento sobre o ensaio visual Ficção nas coisas (vídeo). Blog do IMS, 2012a. 1h1omin. Son. Color. Português. Disponível em http://www.blogdoims.com.br/ videos/.

. Ficção nas coisas (ensaio visual). Serrote. Rio de Janeiro: Instituto Moreira Salles, n.10, março de 2012b.

. L de livro. Serrote. Rio de Janeiro: Instituto Moreira Salles, n.13, março de 2013.

Entrevista a Ligia Canongia. In: Mar nunca nome. Catálogo. Rio de Janeiro:

Centro Cultural Light, 1998.

. Salas e abismos. São Paulo: Cosac Naify, 2009.

. Waltercio Caldas. São Paulo: Cosac Naify, 2001.

DERRIDA, J. Gramatologia. São Paulo: Perspectiva, 2011.

GULLAR, F. Tentativa de compreensão (1959). In: AMARAL, A. (org.). Projeto construtivo brasileiro na arte. Rio de Janeiro: Museu de Arte Moderna; São Paulo: Pinacoteca do Estado, 1977.

NAVAS, A. M. À luz do olhar. In: CALDAS, W. Livros. Catálogo. Porto Alegre: Museu de Arte do Rio Grande do Sul Aldo Malagoli, São Paulo: Pinacoteca, 2002.

OSORIO, L. C. Entre o ler e o ver: a forma-livro na arte de nosso século e seu desdobramento na arte brasileira contemporânea: Waltercio Caldas e Artur Barrio. In: SÜSSEKIND, F.; DIAS, T. (org.). A historiografia literária e as técnicas da escrita: do manuscrito ao hipertexto. Rio de Janeiro: Casa de Rui Barbosa e Vieira e Lent, 2004.

PÉREZ-BARREIRO, G. Waltercio Caldas: o ar mais próximo e outras matérias. Porto Alegre: Fundação Iberê Camargo, 2012.

POUND, E. A arte da poesia: ensaios escolhidos. São Paulo: Cultrix, Editora da Universidade de São Paulo, 1976.

RANCIÈRE, J. L'espace des mots: de Mallarmé à Broodthaers. Nantes: Musée de Beaux-Arts de Nantes, 2005.

SALZSTEIN, S. Acima e abaixo do horizonte. In: CALDAS, W. Salas e abismos. São Paulo: Cosac Naify, 2009.

Waltercio Caldas. In: CALDAS, W. Ciclo de escultura: Waltercio Caldas. Catálogo. São Paulo: Funarte, 1988.

. Livros, superfícies rolantes. In: CALDAS, W. Livros. Catálogo. Porto Alegre: Museu de Arte do Rio Grande do Sul Aldo Malagoli, São Paulo: Pinacoteca, 2002.

VENÂNCIO FILHO, P. Espaço solúvel. In: CALDAS, W. Salas e abismos. São Paulo: Cosac Naify, 2009. 


\section{Notas}

* Professora da Escola de Belas Artes e do Programa de Pós-Graduação em Artes Visuais da Universidade Federal do Rio de Janeiro (PPGAV / EBA-UFRJ). E-mail: ana.mannarino@eba.ufrj.br. ORCID: https:// orcid.org/0000-0001-9720-9502.

1 Todas as obras reproduzidas neste artigo são para fins de estudo e crítica nos termos do art. 46 Inc III e VIII da Lei 9610/98.

2 "Essas palavras são quase cifras. Queria dar-lhes quase um caráter numérico. Como fazer com que uma frase seja uma cifra numérica?" (Caldas, 2012a).

30 texto "Tentativa de compreensão", de Ferreira Gullar, que desenvolve o tema do "não-objeto", publicado no mesmo ano da I Exposição de Arte Neoconcreta (1959), identifica o não-objeto e o "aparecer": "o espaço da tela não preexiste à obra: ele é diretamente arrancado de sua condição material, inumana, para o plano de expressão. Como potencialidades interiores, as formas-cor se espacializam ali pela primeira e única vez. Nada se coloca sobre elas, e o trabalho cessa com a sua aparição. (...) São experiências elaboradas que se concretizam diretamente no espaço - e que transcendem a ele. São um novo objeto que se distingue dos objetos por se concluírem em puro aparecimento: o não-objeto" (Gullar, 1977:57).

Texto recebido em julho de 2021. Aprovado em agosto de 2021 